\title{
SURFACE DAMAGE OF STRUCTURAL CERAMICS: IMPLICATIONS FOR WEAR MODELING*
}

\author{
O. O, AJAYI and K. C. LUDEMA
}

Mechanical Engineering Department, University of Michigan, Ann Arbor, MI 48109-2125 (U.S.A.)

(Received October 16, 1987; accepted February 11, 1988)

\section{Summary}

The reason for the failure of the fracture toughness approach to wear modeling for ceramics is that the assumed linking of the radial and lateral cracks does not often occur. There is indeed wear in sliding but this is due to the fracture and fragmentation of material nearer the surface than the radial and lateral cracks. This scale of fracture is of the order of grain sizes whereas the radial and lateral cracks are of the order of the size of indentations and are usually below the indentation.

These conclusions were reached by observing the damage to four commercial ceramic materials, after indentation and after sliding. The four ceramic materials were hot-pressed $\mathrm{Si}_{3} \mathrm{~N}_{4}$, hot-pressed $\mathrm{SiC}$, sintered $\mathrm{Al}_{2} \mathrm{O}_{3}$ and sintered $\mathrm{ZrO}_{2}$. Tests were done in air, water, aqueous acid and aqueous base. The surfaces of the specimens were "finished" by four different abrasive operations before the test, thereby providing four different states of surface roughness and stress state.

All of the materials showed both large scale (macro) and small scale (micro) damage. There were major differences in micro-damage but only minor or negligible differences in macro-damage. The latter provide the information from which hardness and fracture toughness are calculated.

\section{Introduction}

Ceramic materials are increasingly specified for tribological applications. They are being considered for use in the adiabatic diesel engines $[1-3]$, and they have been used for some time in gas turbine engines $[4,5]$, cutting tools [6-8], roller and slider bearings, replacement hip joints and

*Paper presented at the International Conference on Wear of Materials, Houston, TX, U.S.A., April 5 - 9, 1987. 
numerous other applications in which wear is a problem. In fact ceramic materials are the only solution to some wear problems, particularly those at high temperature and in severe chemical environments.

There are few guidelines for selecting ceramic materials for either a desired friction or wear rate. Thus many engineers resort to the simple laboratory bench testers to obtain useful numerical values. Unfortunately, these results can rarely be used directly to solve practical problems because laboratory bench testers rarely simulate practical conditions. Even the ranking among several materials for wear resistance taken from a bench tester does not often apply to practical situations.

There are many papers in the literature on the wear of ceramic materials but the great majority emphasize the relationship between the wear rate and the some operating parameters, such as applied load, sliding speed or type of abrasive [9-12]. Often the wear of ceramic materials is reported in the literature invoking the traditional and phenomenological classifications: abrasive wear, adhesive wear, erosive wear, sliding wear etc. There have been few papers that connect material properties with wear mechanisms.

In ceramic materials, three mechanisms of material removal have been reported. These are plastic deformation, brittle fracture and a "tribochemical" mechanism.

Although ceramic materials are considered to be brittle, plastic deformation has been observed during static and sliding contact. Plastic strains produce broadening of lines in the X-ray diffraction patterns [13], and dislocation arrays and micro-twins, all of which have been seen in layers immediately below the worm surface of both $\mathrm{Si}_{3} \mathrm{~N}_{4}$ [14] and $\mathrm{SiC}$ [15]. Cathodoluminescence has been seen in worn surfaces [16] which also indicates plastic deformation. Plasticity in otherwise brittle materials occurs through the inhibition of fracture by hydrostatic pressure associated with concentrated contact of surfaces [17]. Thus plastic flow is seen in some cutting processes [13], some fatigue processes [18] and in "mild" wear processes [19]. Some authors have suggested, but not shown conclusively, that plasticity should be enhanced by frictional heating which has the effect of reducing the yield strength of materials [20,21].

A second mechanism of material removal is a "tribochemical" mechanism. This mechanism involves interfacial chemical reaction at the sliding interface, followed by removal of material by sliding contact. An example is the oxidation of $\mathrm{Si}_{3} \mathrm{~N}_{4}$ in water to form $\mathrm{SiO}_{2}$, which is easily removed $[11,22]$. Another example is the observation that some water-lubricated $\mathrm{SiC}$ wears up to three times as rapidly as in the dry sliding case. These may not be cases of the operation of a unique mechanism of wear as much as an enhancement of wear by chemical change.

The third mechanism, and perhaps the most important, is brittle fracture. Most papers that attempt to relate wear to fracture properties infer wear rates from the type of damage that is seen in static indentation studies. Two types of cracks have been observed: those that are normal to the 


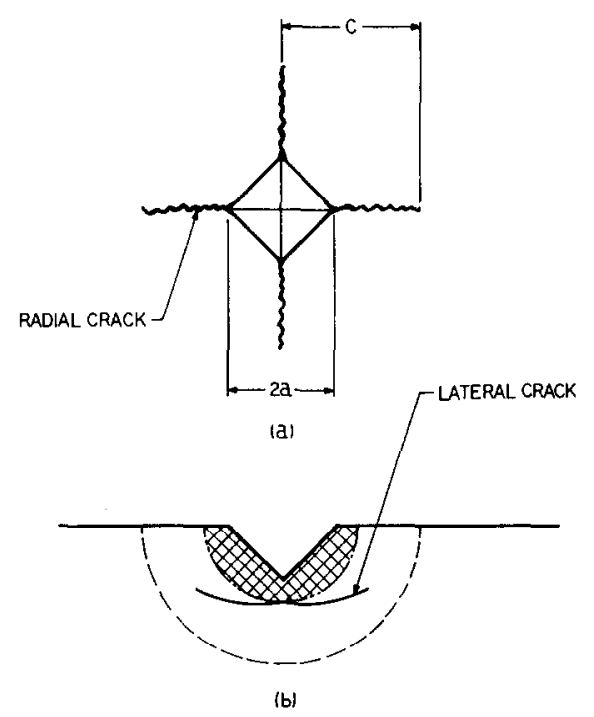

Fig. 1. Sketch of the crack systems formed during identation of brittle materials. (a) Radial cracks emanating from the corners of the identation. (b) The lateral cracks.

surface and extend in a radial direction from the small region of contact, and lateral cracks which are parallel to the surface but relatively deep in the material $[23,24]$. These two types of cracks are sketched in Fig. 1. Evans and Wilshaw [25] showed that radial cracks in brittle materials initiate and partly develop during the loading half-cycle of indentation. Crack growth is attributed to the development of an elastic-plastic stress field, beneath a tip blunting hydrostatic core, with cracks propagating on the plane normal to maximum principal tensile stress. They also showed that the lateral cracks usually (but not always) initiate and propagate during the unloading half of the cycle and are driven by a residual elastic-plastic stress field. Reverse plasticity is assumed to not occur, however. The interactions of the lateral and radial cracks are said to result in material removal [23 - 26].

Several wear models, based on the fracture mechanics approach, assume that the damage due to indentation is also operative in sliding [25, $27-29]$. The wear, or material removal mechanism, is thought to be the fragmenting out of all of the materials, fractured in the normal and lateral directions, along the line of sliding. Equations are given to describe these events, and they are written in terms of the hardness $H$, the elastic modulus $E$ and the fracture toughness $K_{c}$ of the material. These values are usually determined from the deformed zone dimension $2 a$ and the macrocrack length $c$ with applied load $P_{n}$ as shown in Fig. 1.

Evans and Marshall [28] proposed one such model. Their equation relales the wear volume $V$ per unit of sliding distance $s$ to the fracture toughness and hardness as follows:

$V=P_{n}{ }^{1.125} K_{c}^{-0.5} H^{-0.625}\left(\frac{E}{H}\right)^{0.8} s$ 
Unfortunately, none of these wear models is verified by experimental results $[27,30$ - 32]. Some qualitative correlation of such a model and experimental data have been reported for glass $[17,25,28]$ perhaps because glasses are non-crystalline.

The work reported below arose from attempts to verify the fracturemechanics-based models for the wear of ceramic materials. It was found that the major failing of the fracture mechanics approach is that it is based on the macro measurements $2 a$ and $c$, which are material responses to a very different stress field than that which causes much of the fragmentation of material in concentrated contact. The latter is seen on a micro-scale, in and around indentations.

Two types of experiments were done. The first was a static indentation test using a diamond pyramid indentor. The second used a diamond sphere which was loaded and slid against the ceramic materials. In this study four ceramic materials were used. Further, since the literature contains papers from many laboratories in which specimens are prepared and tested in many different ways, several conditions were imposed on the materials in these tests. The surfaces of the four ceramic materials were prepared by four different coarsenesses of abrasives, and tested in four environments with five different loads. Each indentation and the track due to a sliding diamond were studied microscopically and differences among the various materials are presented.

\section{Experimental details}

The materials for this study, their sources and properties are listed in Table 1. The materials are of industrial grade, polycrystalline $\mathrm{SiC}, \mathrm{Si}_{3} \mathrm{~N}_{4}$, $\mathrm{Al}_{2} \mathrm{O}_{3}$ and $\mathrm{ZrO}_{2}$. It should be noted that none of the four materials is pure. Actually, no commercial ceramic material is pure because to date few pure materials have been successfully sintered. Proprietary "sintering aids", in various amounts are added, as shown in Table 2, thereby producing different-behaving ceramic materials from different suppliers. This makes the literature on ceramic wear confusing. Further confusion arises from attempts to correlate the surface damage of polycrystalline material with that in single crystals.

Of the four ceramic materials, all but $\mathrm{SiC}$ have second phases between the grains. The $\mathrm{SiC}$ has a small amount of aluminum added, which is found in the grain but preferentially near the grain interfaces and "aids sintering".

Four different processes were used to prepare the surfaces, each resulting in different surface roughnesses as shown in Table 1. Process A produces the smoothest surface and was obtained with a series of $\mathrm{SiC}$ abrasive papers down to 600 grit, followed by polishing with a series of diamond abrasives down to $0.25 \mu \mathrm{m}$. Process B was a series of SiC paper down to 600 grit, process $C$ used a series to 320 grit, and process $D$ used a series to 240 grit abrasive paper. A Proficorder stylus tracer was used to measure the surface 


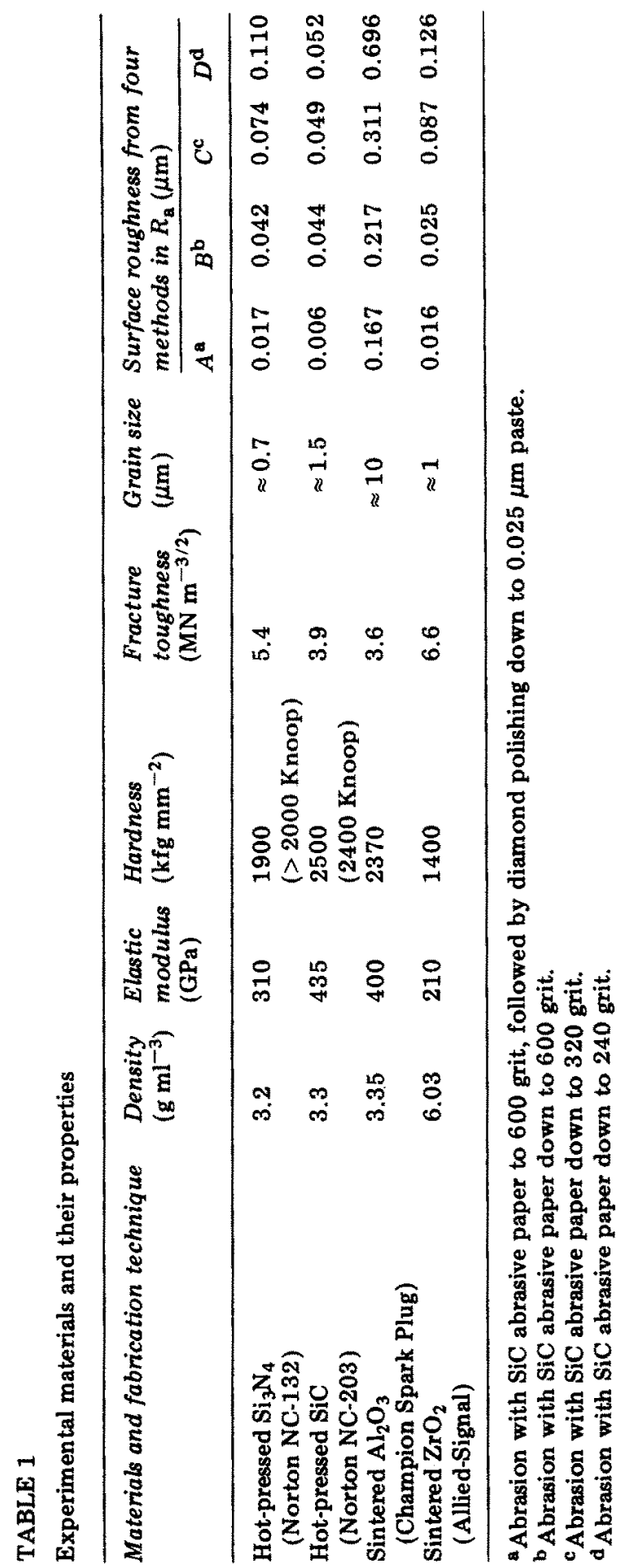


TABLE 2

Common ceramic materials, listing commercial "sintering aids" and the phases in the grain boundaries ${ }^{a}$

\begin{tabular}{|c|c|c|c|c|}
\hline Material & Sintering aid & Major phases & Minor phases & $\begin{array}{l}\text { Grain boundary phase } \\
\text { (glassy) }\end{array}$ \\
\hline $\begin{array}{l}\text { Hot-pressed } \\
\mathrm{Si}_{3} \mathrm{~N}_{4}\end{array}$ & $\begin{array}{l}\mathrm{MgO}^{\mathrm{b}} \\
\mathrm{Y}_{2} \mathrm{O}_{3} \\
\mathrm{CeO}_{2}\end{array}$ & $\begin{array}{l}\beta-\mathrm{Si}_{3} \mathrm{~N}_{4} \\
\beta-\mathrm{Si}_{3} \mathrm{~N}_{4} \\
\beta-\mathrm{Si}_{3} \mathrm{~N}_{4}\end{array}$ & $\begin{array}{l}\mathrm{Si}_{2} \mathrm{~N}_{2} \mathrm{O} \\
\mathrm{Si}_{2} \mathrm{~N}_{2} \mathrm{O} \\
\mathrm{Si}_{2} \mathrm{~N}_{2} \mathrm{O}\end{array}$ & $\begin{array}{l}\mathrm{Mg}_{2} \mathrm{SiO}_{4}+\mathrm{MgSiO}_{3} \\
\mathrm{Y}_{2} \mathrm{Si}_{2} \mathrm{O}_{7} \\
\mathrm{Ce}_{2} \mathrm{Si}_{2} \mathrm{O}_{7}\end{array}$ \\
\hline Hot-pressed & $\mathrm{Al}^{\mathbf{b}}$ & $\alpha-\mathrm{SiC}$ & $\begin{array}{l}\text { Al segregation to } \\
\text { grain boundary }\end{array}$ & - \\
\hline $\mathrm{SiC}$ & B & $\alpha-\mathrm{SiC}$ & $\begin{array}{l}\text { B segregation to } \\
\text { grain boundary }\end{array}$ & - \\
\hline $\mathrm{Al}_{2} \mathrm{O}_{3}$ & $\begin{array}{l}\mathrm{MgO}^{\mathrm{b}} \\
\mathrm{CaO}\end{array}$ & $\begin{array}{l}\alpha-\mathrm{Al}_{2} \mathrm{O}_{3} \\
\alpha-\mathrm{Al}_{2} \mathrm{O}_{3}\end{array}$ & $\begin{array}{l}\mathrm{MgAl}_{2} \mathrm{O}_{4} \\
\mathrm{CaAl}_{2} \mathrm{Si}_{2} \mathrm{O}_{7}\end{array}$ & $\begin{array}{l}\mathrm{MgAl}_{2} \mathrm{O}_{4} \\
\mathrm{CaAl}_{2} \mathrm{Si}_{2} \mathrm{O}_{7}\end{array}$ \\
\hline $\mathrm{ZrO}_{2}$ & $\begin{array}{l}\mathrm{Y}_{2} \mathrm{O}_{3}-\mathrm{TZP}^{\mathrm{b}} \\
\mathrm{Y}_{2} \mathrm{O}_{3}-\mathrm{PSZ}\end{array}$ & $\begin{array}{l}\text { tetragonal } \mathrm{ZrO}_{2}(\mathrm{ss}) \\
\text { cubic } \mathrm{ZrO}_{2}(\mathrm{ss})\end{array}$ & $\begin{array}{l}\text { cubic } \mathrm{ZrO}_{2}(\mathrm{ss}) \\
\text { tetragonal } \mathrm{ZrO}_{2} \\
(\mathrm{ss})\end{array}$ & - \\
\hline
\end{tabular}

${ }^{a}$ All of these materials may also contain $3 \cdot 5 \mathrm{wt} . \%(<1$ at.\%) of metallic impurities from processing.

${ }^{b}$ Materials used for the present work.

roughness. It should be noted that process $A$, for example, did not produce the same roughness on all of the materials. The specimens could have been prepared to the same surface roughnesses for comparison but each would require a different process. A decision was made therefore to use the preparation method as the common variable since this is most often given in the literature on wear testing. Micrographs of the materials show the presence of scratches due to surface preparation for relatively soft $\mathrm{ZrO}_{2}$ and for $\mathrm{Si}_{3} \mathrm{~N}_{4}$. There were no scratches on $\mathrm{SiC}$, the hardest material, rather the surface roughness is due to micropits and voids which are formed by grain removal. $\mathrm{Al}_{2} \mathrm{O}_{3}$ shows no scratches either but has voids and pits that might have been created by grain removal or are pores that were present from processing the material. In addition, a second phase material $\mathrm{MgAl}_{2} \mathrm{O}_{4}$ was removed from $\mathrm{Al}_{2} \mathrm{O}_{3}$, resulting in a higher surface roughness than with the other three materials for the same surface preparation (Fig. 2(c)).

Indentation was done with a Tukon LR microhardness tester fitted with a Vickers diamond tip, using five loads: $0.1,1.0,2.0,3.0$ and $4.0 \mathrm{kgf}$ (approximately $1-39.9 \mathrm{~N}$ ). Some indentations were done on dry surfaces, in air. Other specimens were indented after soaking for $6 \mathrm{~h}$ in three liquids, namely, distilled water, aqueous acid and aqueous base. After soaking, the indentations were done with thin films of the liquid on the surface.

Sliding tests were performed with the same microhardness tester fitted with a spherical diamond tip of $100 \mu \mathrm{m}$ radius and a moving $(x-y)$ stage. 


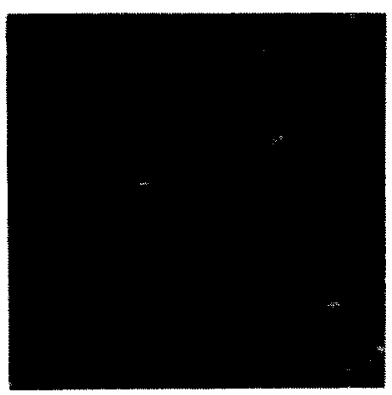

(a)
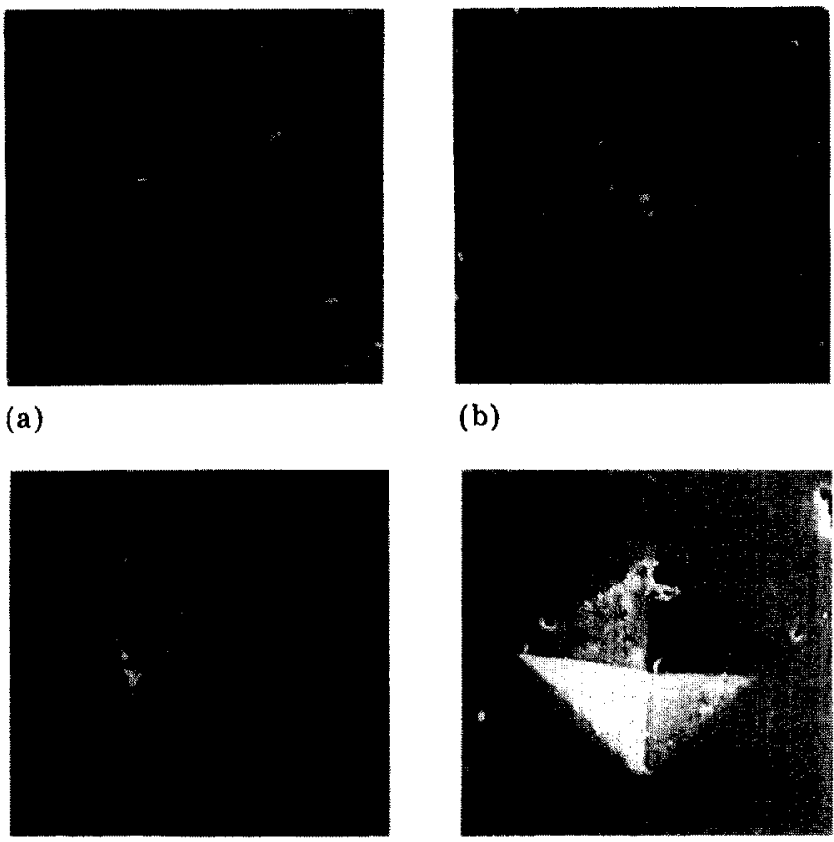

(b)

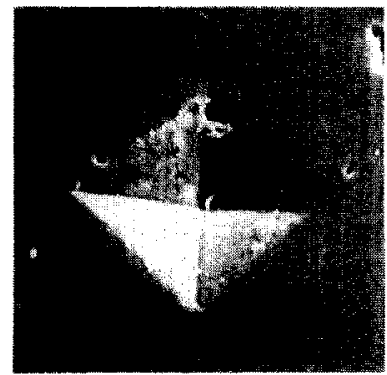

(d)

(c)

Fig. 2. Main view of the identation with a load of $1 \mathrm{kgf}$ on surface preparation $\mathrm{A}$ for the four materials : (a) $\mathrm{Si}_{3} \mathrm{~N}_{4}$; (b) $\mathrm{SiC}$; (c) $\mathrm{Al}_{2} \mathrm{O}_{3}$; (d) $\mathrm{ZrO}_{2}$.

Loads of $0.1,1.0,2.0$, and $3.0 \mathrm{kgf}$ (about $1-30 \mathrm{~N}$ ) were applied and the stage was moved very slowly, at less than $0.1 \mathrm{~mm} \mathrm{~s}^{-1}$. The surfaces were observed after single passes of sliding and after five unidirectional passes. The frictional force was measured with a strain gauge system.

The specimens were examined using a scanning electron microscope, paying particular attention to the indentation and sliding regions in order to identify both the macro and the micro-damage resulting from contact. All of the specimens were coated with gold after testing and before examination to prevent charging in the microscope.

\section{Results}

\subsection{Indentation tests}

We define two scales of indentation damage, namely micro-damage and macro-damage. Macro-damage occurs over a large area, relative to the grain size, and consists essentially of the depression of the indented region and any 
crack systems that may form. Micro-damage occurs at the individual grain level in the material. Major differences between the four materials were seen in the micro-scale and only minor differences were seen in the macro-scale.

Figure 2 is a macro view of the indentation of the four materials, indented when dry, with a load of $1 \mathrm{kgf}$. (The usual range of load in indentation tests is from 1 to $10 \mathrm{kgf}$.) It should be noted that there is little to distinguish the behavior of one from the other, except that the indentation in $\mathrm{SiC}$ is smallest and in $\mathrm{ZrO}_{2}$ is the largest. These dimensions are used to determine the hardness, recall. There is also some difference in the shape of one indentation as will be noted later.

The micro-scale of damage is described in some detail below. However, to clarify the main points of the differences between the materials, Table 3 is presented. Eight distinguishing features or types of surface damage are listed. Numbers 1,2 and 3 are the codes for details in the macro view of damage and the other five refer to micro-damage. The main body of Table 3 then indicates, by number, the types of damage seen at various loads where the surfaces have been prepared by processes A, B, C and D. For example, the $\mathrm{Al}_{2} \mathrm{O}_{3}$ prepared by process $\mathrm{A}$, with $3 \mathrm{kgf}$ applied load was seen to have damage of types 1,2 and 4. However, in addition, this specimen as well as all of the $\mathrm{Al}_{2} \mathrm{O}_{3}$ specimens showed plastic flow (damage type 2) as indicated below the column of numbers. Then in rows below the column of numbers the influence of environment and surface roughness is given.

\subsection{Identification of various types of indentation damage}

Examples of the eight types of damage will now be given. At this point it will not be necessary to connect any particular type of damage with any specific material. The behavior of the material as noted in these experiments may not represent the intrinsic properties of any of the generic ceramics. That is, all $\mathrm{ZrO}_{2}$ may not respond to indentation exactly as was seen in these experiments. Some commercial $\mathrm{ZrO}_{2}$ may respond more like $\mathrm{Al}_{2} \mathrm{O}_{3}$ did in the present experiments and some more like $\mathrm{Si}_{3} \mathrm{~N}_{4}$ did in these experiments. The behavior of specific ceramic materials is controlled strongly by the types and amounts of second (and third) phases present in the material.

Figure 2 shows the macro-damage, in which the first three types of material response of Table 3 may be seen. (All of these were prepared by method $A$ and each has a different appearance because of its different response to the surface preparation.) Figures 2(a) and 2(c) show the most evidence of cracks extending beyond the corners of the indentation (damage type 1). Figure 2(d) shows the most plastic flow and Fig. 2(b) shows the least (damage type 2). Figure 2(d) also shows the greatest amount of barrel shape of indentation (damage type 3 ).

Figure 3 shows the type 4 response, namely grain boundary fracture. This is shown both in $\mathrm{Si}_{3} \mathrm{~N}_{4}$ and in $\mathrm{Al}_{2} \mathrm{O}_{3}$.

Figure 4 shows the type 5 response. The larger scale grain boundary fracture (type 5) is best seen in $\mathrm{SiC}$. 


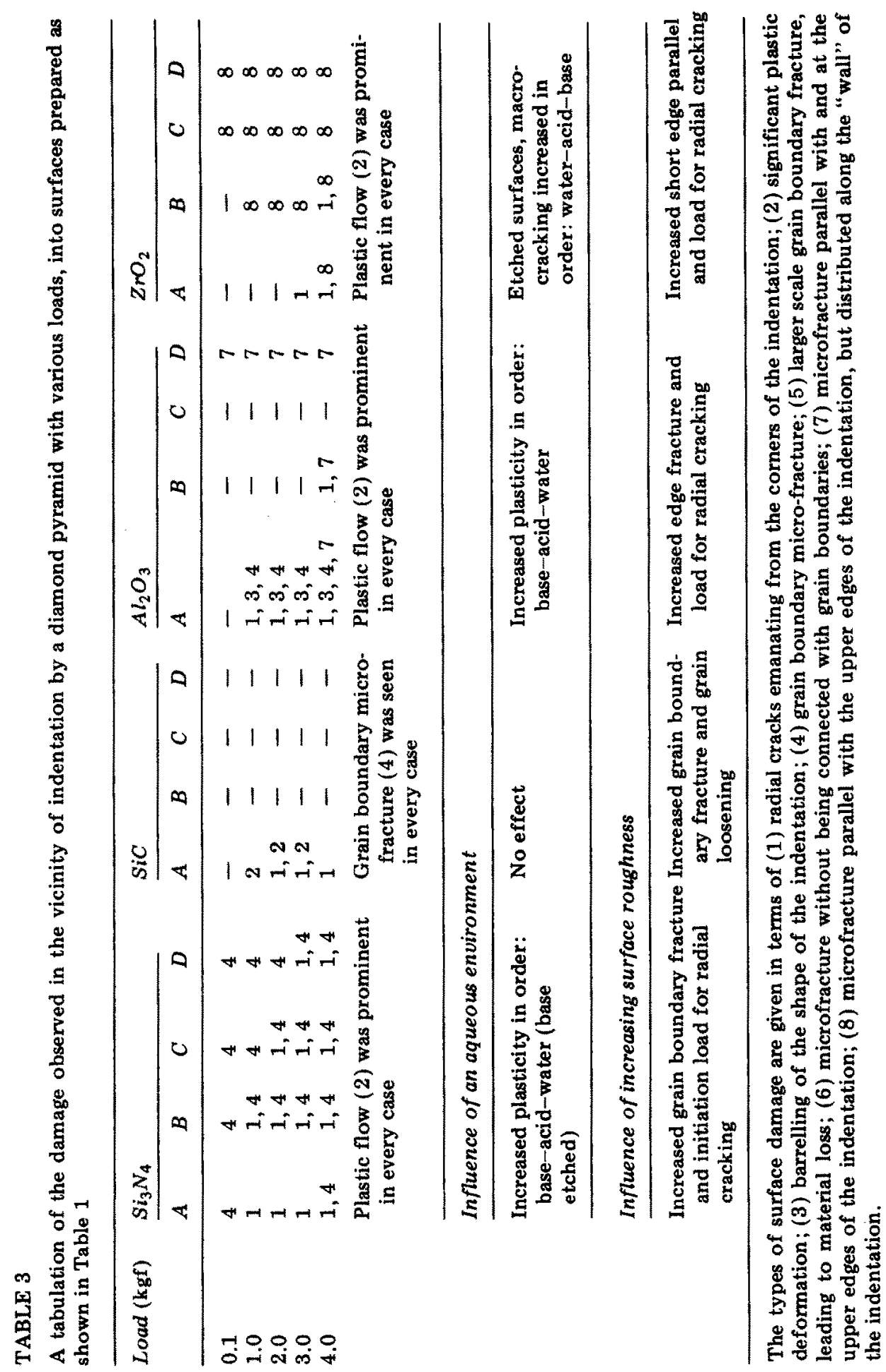




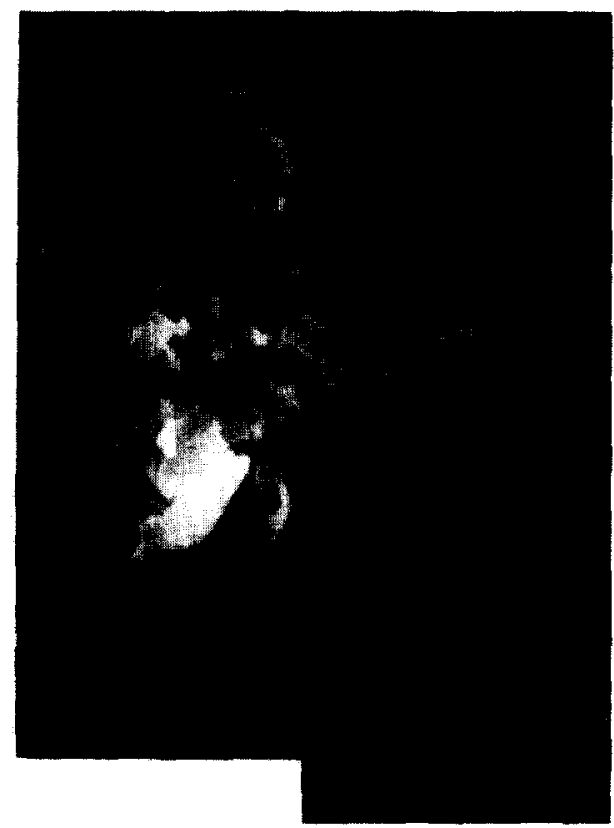

(a)

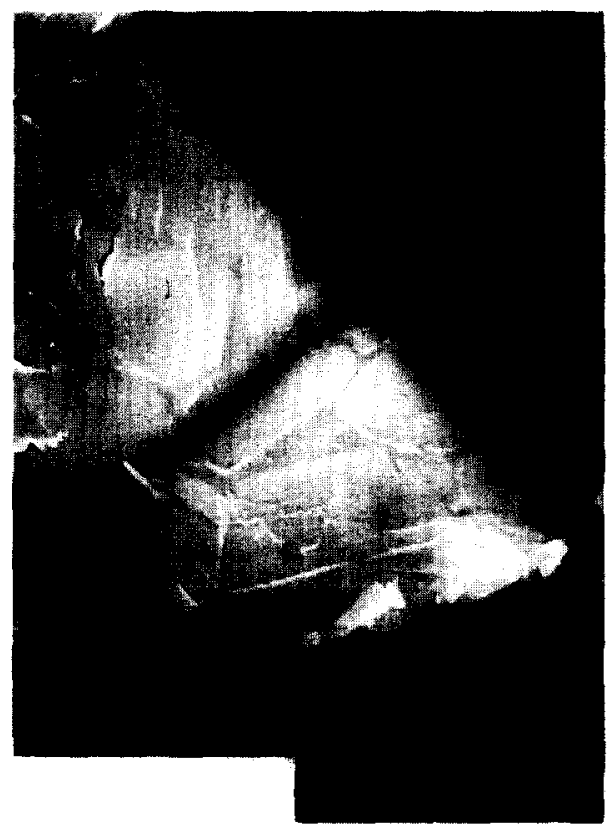

(b)

Fig. 3. Microdamage of grain boundary cracking in the indented region. (a) $\mathrm{Si}_{3} \mathrm{~N}_{4}$ (load $4 \mathrm{kgf}$ surface preparation $\mathrm{A}$ ). (b) $\mathrm{Al}_{2} \mathrm{O}_{3}$ which also shows the slip lines in the grains (load $1 \mathrm{kgf}$ surface preparation $\mathrm{A}$ ).

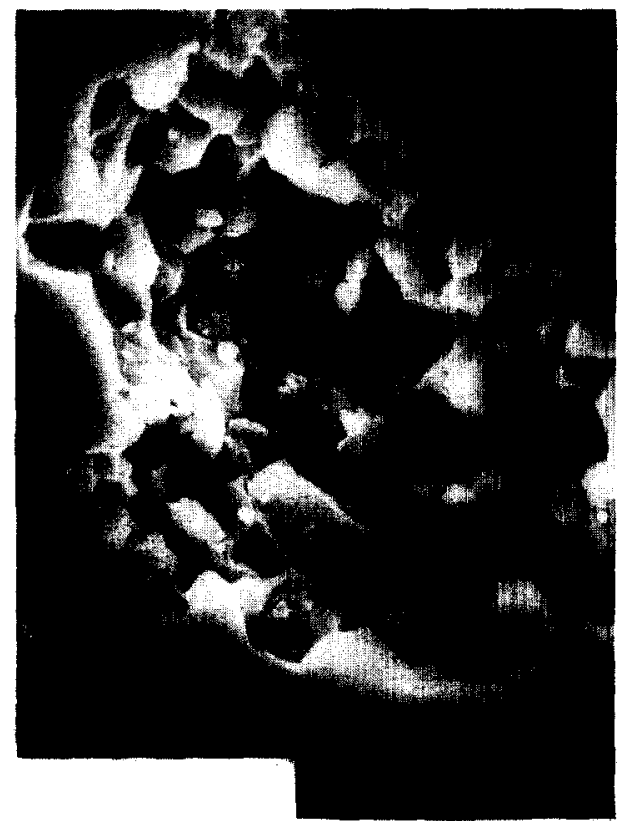

Fig. 4.. Extensive grain boundary damage resulting in material loss in SiC (load $1 \mathrm{kgf}$ surface preparation $B$, indented in water). 

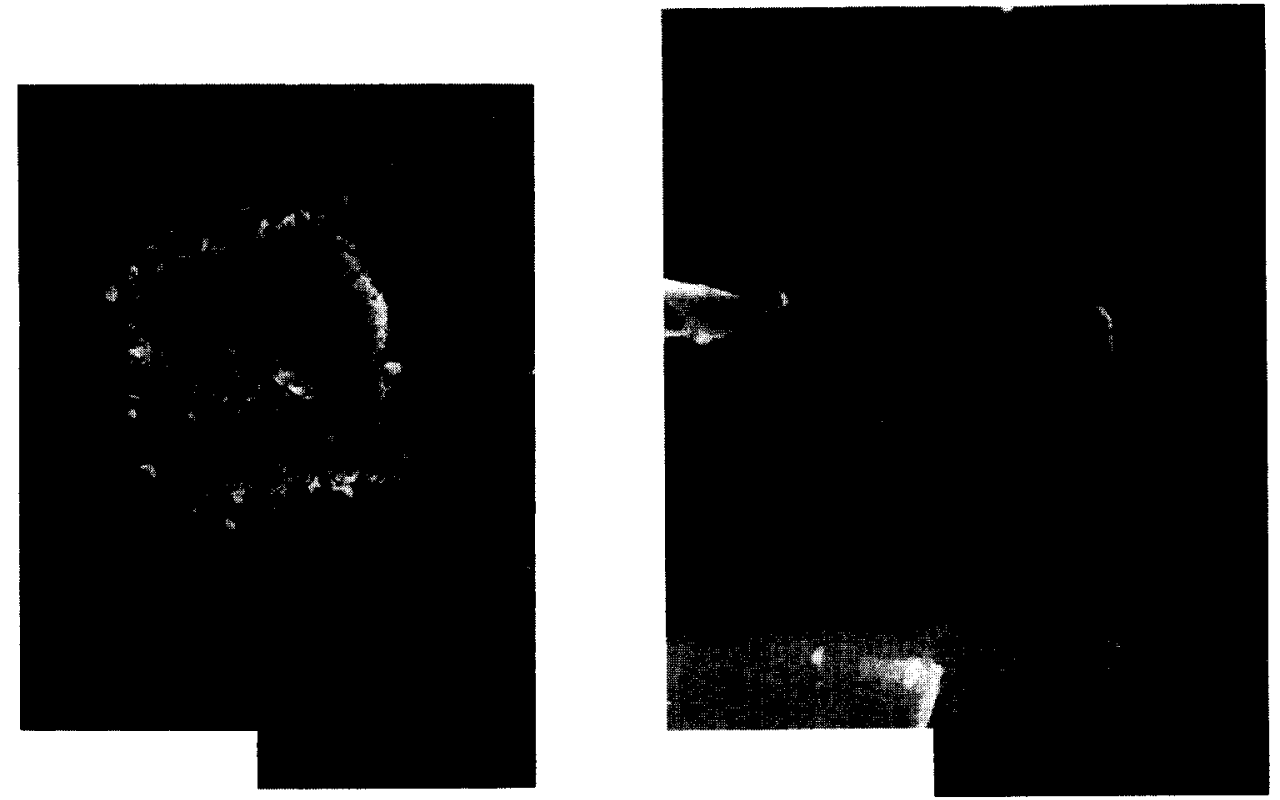

Fig. 5. Edge microfracture around the indentation in $\mathrm{Si}_{3} \mathrm{~N}_{4}$ (load $3 \mathrm{kgf}$ surface preparation D).

Fig. 6. Microcracks along the indentation walls in $\mathrm{ZrO}_{2}$ (load 4 kgf surface preparation A).

Figure 5 shows types 6 and 7 response, namely microfracture apart from the grain boundaries which are parallel with and at the upper edges of the indentation. $\mathrm{Si}_{3} \mathrm{~N}_{4}$ is the best example of this type of damage.

Figure 6 shows the type 8 response, namely microcracking parallel with the upper edges of indentation but distributed along the "wall" of the inden. tation. $\mathrm{ZrO}_{2}$ is the best example of this damage.

\subsection{Sliding tests}

The coefficients of friction during very slow speed sliding for the various materials are listed in Table 4 . For the tests done in air, $\mathrm{ZrO}_{2}$ has the lowest coefficient of friction at 0.3 while $\mathrm{SiC}$ has the highest at 0.6 for single-pass sliding. All the four materials, however, gave a friction coefficient of about 0.6 during the fifth pass. Also in all cases the coefficient of friction was independent of the load and the surface finish.

For the four materials the effect of the aqueous environment was to decrease the friction coefficient. (The calculated elastohydrodynamic fluid film is less than $1 \mathrm{~nm}$.) The decrease was more pronounced in the non-oxide materials. Among the environments, the basic aqueous medium reduced the friction coefficient the most, with the acids and water producing about the same effect. 
TABLE 4

Coefficient of friction and type of sliding damage

\begin{tabular}{|c|c|c|c|c|c|}
\hline \multirow[t]{3}{*}{ Material } & \multicolumn{5}{|c|}{ Environment } \\
\hline & \multicolumn{4}{|c|}{ Single-pass sliding } & \multirow{2}{*}{$\begin{array}{l}\text { All environments } \\
\text { five passes }\end{array}$} \\
\hline & Air & $\begin{array}{l}\text { Distilled } \\
\text { water }\end{array}$ & $\begin{array}{l}\text { Aqueous } \\
\text { acid }\end{array}$ & $\begin{array}{l}\text { Aqueous } \\
\text { base }\end{array}$ & \\
\hline $\mathrm{Si}_{3} \mathrm{~N}_{4}$ & 0.4 & 0.3 & 0.2 & 0.17 & $\approx 0.6$ \\
\hline $\mathrm{SiC}$ & 0.6 & 0.4 & 0.4 & 0.35 & $\approx 0.6$ \\
\hline $\mathrm{Al}_{2} \mathrm{O}_{3}$ & 0.5 & 0.4 & 0.4 & 0.4 & $\approx 0.6$ \\
\hline $\mathrm{ZrO}_{2}$ & 0.3 & 0.3 & 0.2 & 0.2 & $\approx 0.6$ \\
\hline
\end{tabular}

Surface damage due to sliding was very specific to the materials. Table 5 gives a summary of these effects. Specific results are discussed below.

For hot-pressed $\mathrm{Si}_{3} \mathrm{~N}_{4}(\mathrm{NC132})$ the damage to the smoothest surface finish consisted of plastic deformation, up to a load of $2 \mathrm{kgf}$. This deformation resulted in the highlighting of the grain boundaries (Fig. 7(a)). By five passes at $2 \mathrm{kgf}$ load some material was removed by what appeared to be grain boundary failure. At a load of $3 \mathrm{kgf}$, cracks appeared on the surface behind the slider, which are parallel to one another and at a right angle with the sliding direction (Fig. 7(b)). These cracks tend to follow the grain boundaries. There was also microfracture which resulted in the formation of fine particle debris at the edges of the sliding track. The extent of the deformation and edge microfracture increased with increasing load and surface roughness. In multipasses, more grains were removed. The short parallel cracks became more numerous as the load increased and as the number of passes increased.

In the liquid environment, the plastic deformation was more extensive than in air. Edge microfracture was substantially reduced. By five passes, starting with a load of $1 \mathrm{kgf}$, material was removed from the wear track by what appeared to be a fatigue mechanism. Material removal followed the grain boundaries (Fig. 7(c)). The basic environment had the greatest effect, followed by distilled water and then acid. More damage (material removal) occurred in these three liquids than occurred in air.

Hot-pressed SiC (NC-203) showed no plastic deformation whatsoever. The damage consisted essentially of grain removal (Fig. 8(a)), the extent of which increased with increasing load and number of passes. After several passes fine particle debris accumulated in the wear track (Fig. 8(b)). As the surface roughness increases, edge microfracture was also observed. This resulted in the formation of fine debris along the edges of the track (Fig. $8(c))$. Liquid environments produced more grain removal during multiple passes then occurred in air. Water and base seemed to have about the same order of effect while the acid produced less effect. 


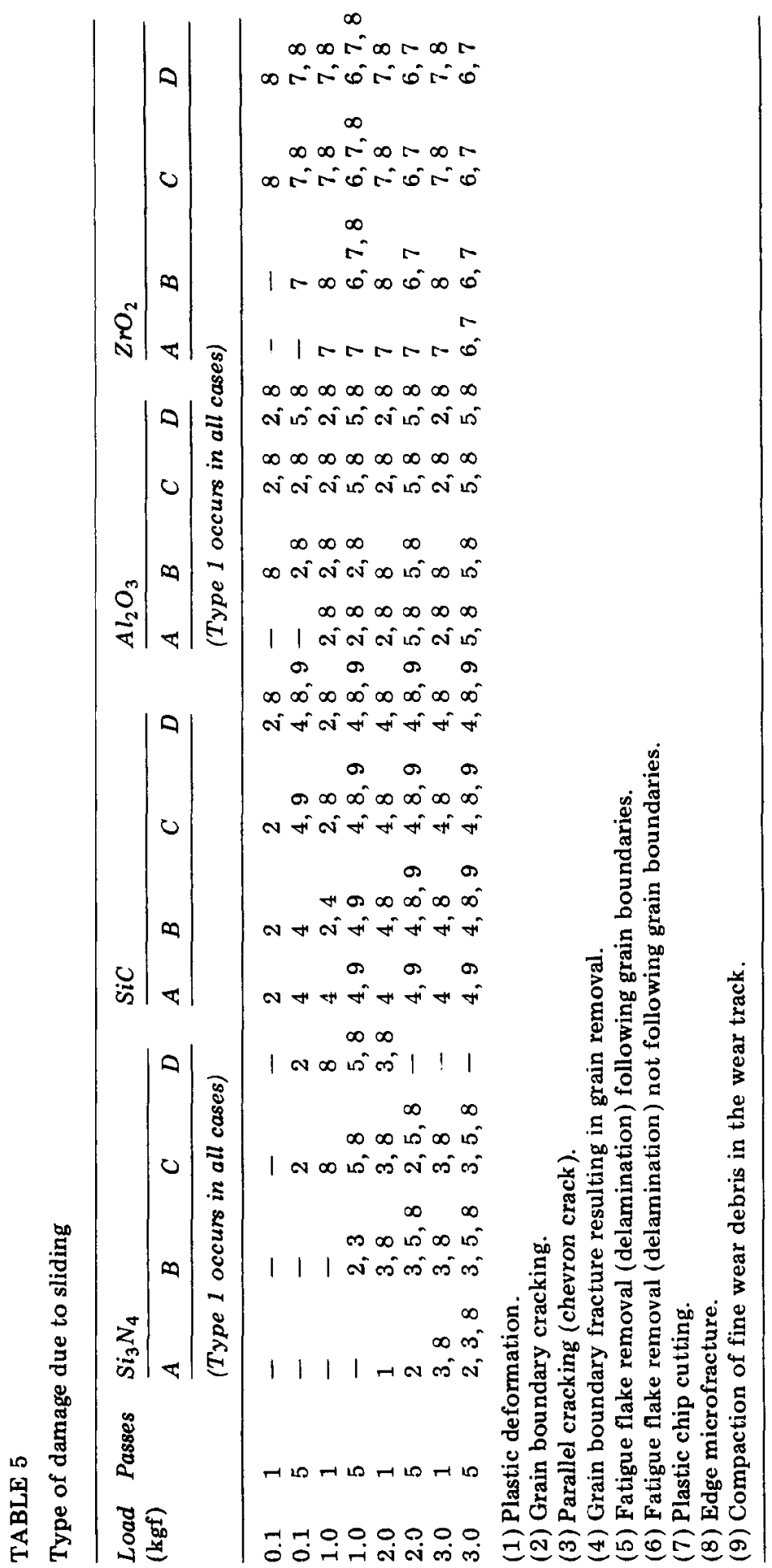




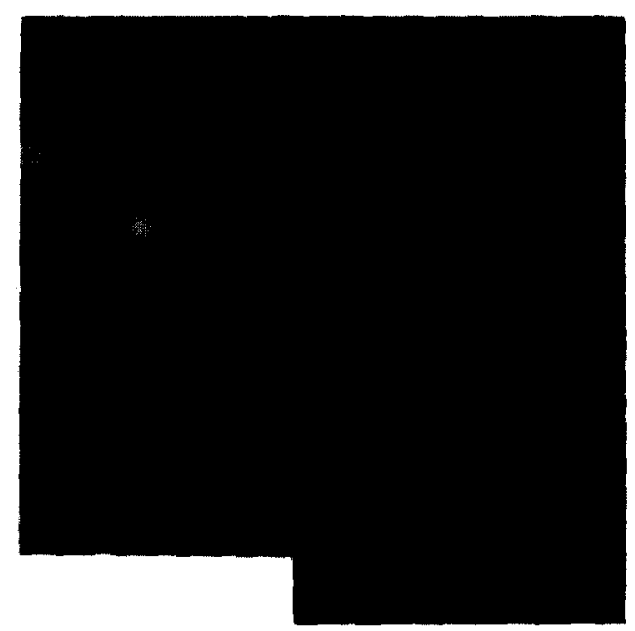

(a)

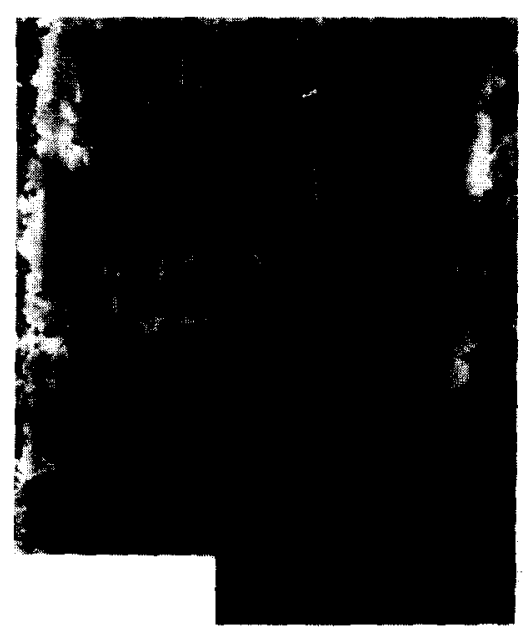

(b)

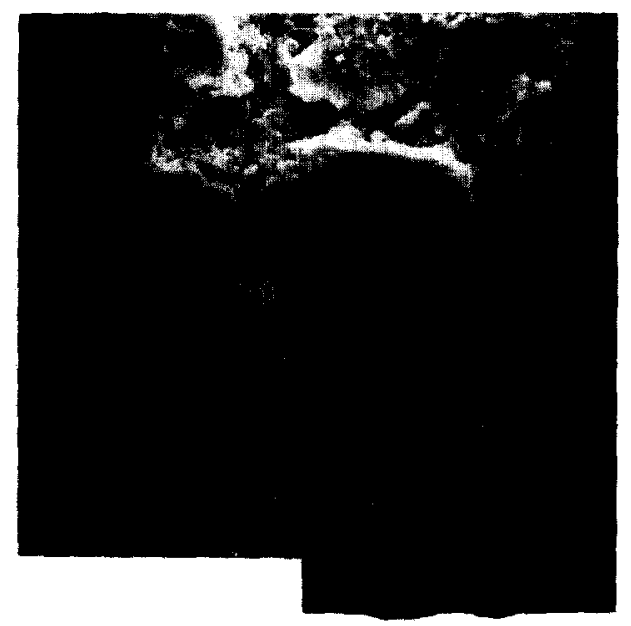

(c)

Fig. 7. Damage due to sliding of spherical diamond in $\mathrm{Si}_{3} \mathrm{~N}_{4}$. (a) Plastic deformation highlighting the grain boundaries (1 kgf load, one pass, surface preparation B). (b) Parallel (chevron) cracks (load $3 \mathrm{kgf}$, one pass, surface preparation A). (c) Fatigue flake removal (delamination) in the sliding track. (Load $2 \mathrm{kgf}$, five passes, surface preparation $B$ in acid environment).

The damage in $\mathrm{Al}_{2} \mathrm{O}_{3}$ consisted of plastic deformation with some grain boundary microfracture (Fig. $9(\mathrm{a})$ ). The extent of this deformation increased with increasing load and surface roughness. Fine debris was also observed and it became more pronounced with increasing surface roughness and load (Fig. 9(b)). By five passes and at a load of $3 \mathrm{kgf}$ for surface finish $\mathrm{A}$ and lower loads for rougher surfaces, fatigue-like material removal was observed. This occurs after plastic deformation and the fracture follows the grain 


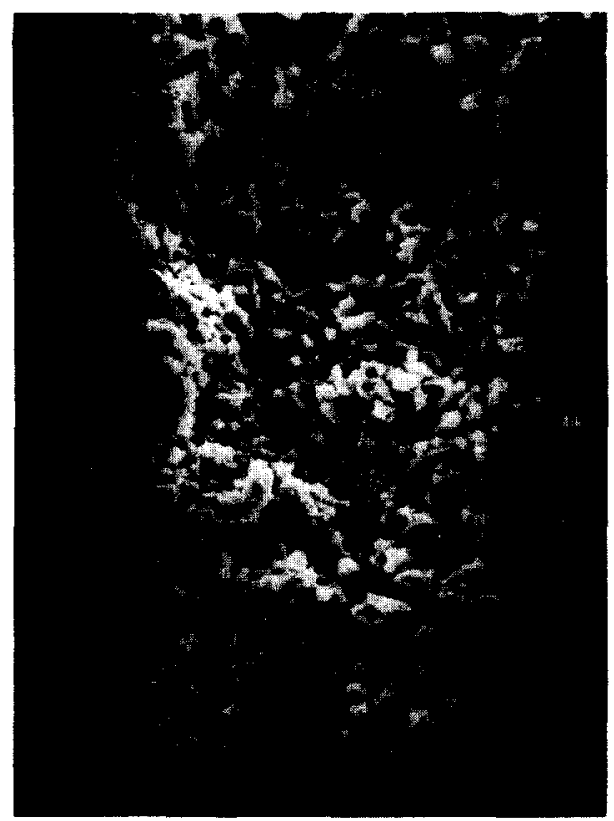

(a)

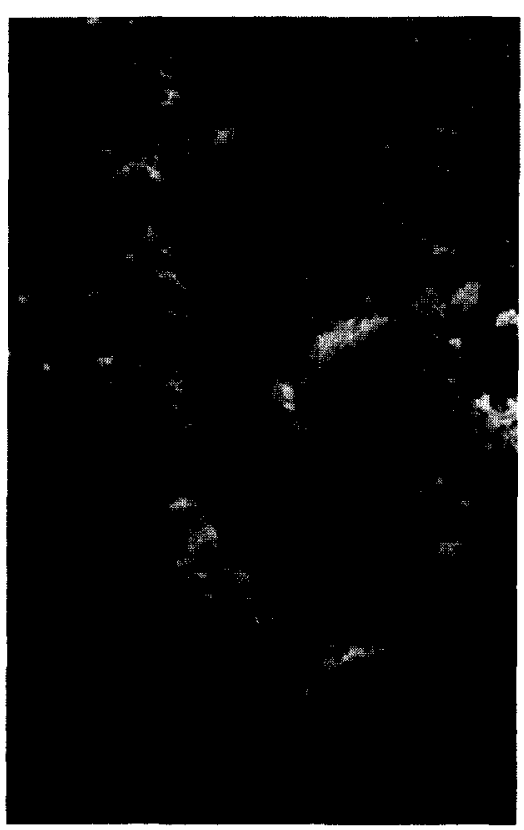

(c)

Fig. 8. Sliding damage in $\mathrm{Si}_{3} \mathrm{~N}_{4}$. (a) Material removal by extensive grain boundary fracture (load $1 \mathrm{kgf}$, two passes, surface preparation A). (b) Fine particle debris being compacted in the wear track (load $1 \mathrm{kgf}$, five passes, surface preparation A). (c) Edge microfracture in rougher surface in addition to extensive grain boundary cracking (load $1 \mathrm{kgf}$, one pass, surface preparation $\mathrm{C}$ ). 


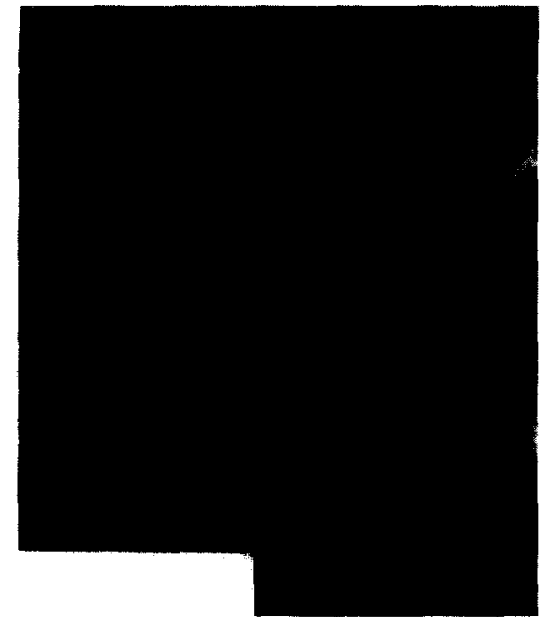

(a)

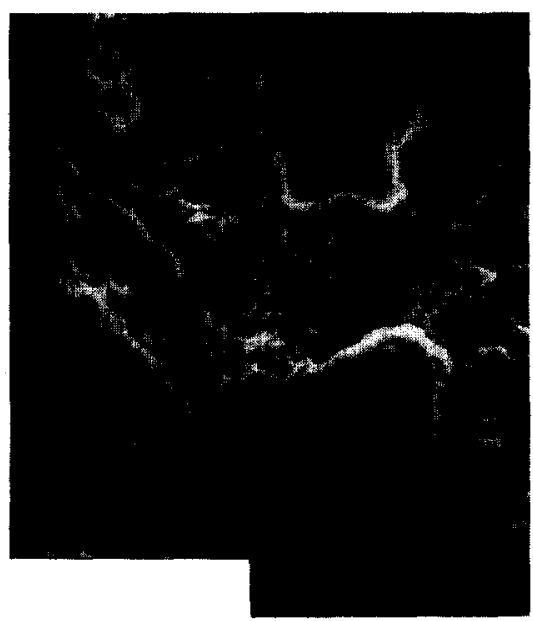

(c)

Fig. 9. Sliding damage in $\mathrm{Al}_{2} \mathrm{O}_{3}$. (a) Grain boundary microcracking (load $1 \mathrm{kgf}$, five passes, surface preparation A). (b) Plastic deformation with edge microfracture (load $1 \mathrm{kgf}$, one pass, surface preparation B). (c) Fatigue flake removal (delamination) in the wear track following the grain boundaries (load $1 \mathrm{kgf}$, five passes, surface preparation $B$ in acid).

boundaries. This kind of material removal was more pronounced in all three aqueous environments at about the same order (Fig. 9(c)).

The damage in $\mathrm{ZrO}_{2}$ consisted of extensive plastic deformation and material removal by chip formation (Fig. 10(a)). The extent of plastic deformation and cutting also increased with load and surface roughness. After many passes, however, a fatigue kind of failure was also seen (Fig. 10(b)). 


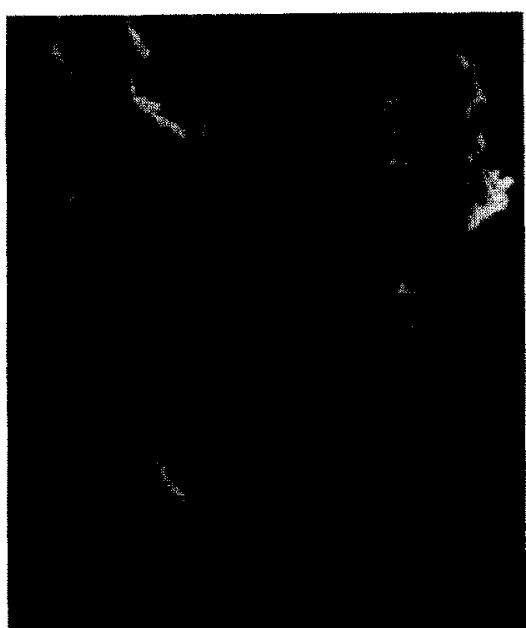

(a)

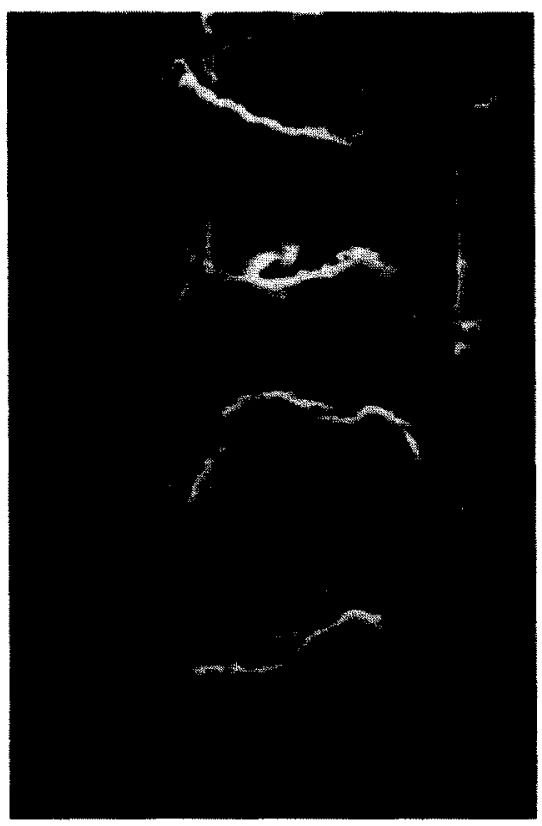

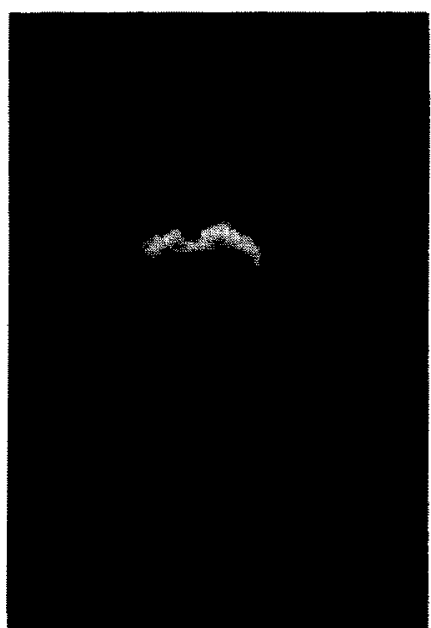

(b)

(c)

Fig. 10. Sliding damage in $\mathrm{ZrO}_{2}$. (a) Plastic deformation with plastic chip cutting (load $3 \mathrm{kgf}$, five passes, surface preparation C). (b) Fatigue initiation in the wear track following plastic deformation (load $4 \mathrm{kgf}$, five passes, surface preparation A). (c) Fatigue flake removal (delamination from the wear track) (load $2 \mathrm{kgf}$, five passes, surface preparation $B$ in acid).

This eventually results in material removal from the wear track as shown in Fig. 10(c). This fatigue process was again more pronounced in the aqueous environments than in air. 


\section{Discussion}

Three points are raised as a result of this investigation. The first is that there are a wide range of deformation and fracture types that occur on the surfaces of the ceramic materials of this investigation. The second is that the surface damage and material loss mechanisms appear not to be related to the materials properties measured by the methods of fracture toughness. There was, incidentally, no attempt to verify the existence of the radial and lateral cracks. The third is that though ceramic materials are thought to be chemically resistant to most environments, even water has a large effect on their micro-fracture and wear.

\subsection{Non-homogeneous structures in ceramic materials}

The different types of damage can be explained by the response of the non-homogeneous microstructures of the materials to the non-homogeneous strain field imposed by an indentor. We will discuss the sources of the anisotropy first, for specific tested materials.

Hot-pressed $\mathrm{Si}_{3} \mathrm{~N}_{4}$, with an $\mathrm{MgO}$ sintering aid (which was used in this study, see Table 2), consists of grains of hexagonal crystalline $\beta-\mathrm{Si}_{3} \mathrm{~N}_{4}$ containing a second minor phase $\left(\mathrm{Si}_{2} \mathrm{~N}_{2} \mathrm{O}\right)$, which are bonded or joined by a thin film of glassy magnesium silicate. The grain boundary phase will therefore deform by viscous flow while the grain will deform by slip. This difference in modes of strain will highlight grain boundaries, as was seen. The two phases will also fracture differently. Grain boundary cracking was seen both in and around the indented region (Fig. 3(a)). The latter increased with increasing initial surface roughness. $\mathrm{Si}_{3} \mathrm{~N}_{4}$ had macro-cracks extending from the corner of the indented region.

Hot-pressed $\mathrm{SiC}$ showed extensive grain boundary failure leading to material removal and grain loosening in the indented region with no apparent plastic deformation (Fig. 4). The surface preparation method and environment of the indentation test had a very large effect on the failure that occurred in static indentation but not in sliding. The aluminum-doped hot-pressed $\mathrm{SiC}$ (used for this study) contains no grain boundary phase, but there is a preferential presence of aluminum towards the grain boundary [33]. Segregation of impurity atoms to a grain boundary embrittles it and may be the cause of the extensive grain boundary failure seen. The increased intergranular failure with the rougher surfaces is likely owing to the residual stresses from surface preparation.

For $\mathrm{Al}_{2} \mathrm{O}_{3}$, macro-cracks originating from the corner of the indented region were observed at some loads, and there was plastic deformation and grain boundary cracking within the indented region. Deformation occurs within the grain, which has a hexagonal structure. The barrelling of the indented region as well as the crack initiation in the grain boundaries is due to the anisotropic deformation of the grains within the region [34]. This may be explained by referring to slip systems. The plastic deformation in the grain is by slip as may be seen from the shear bands in Fig. 3(b). For 
$\mathrm{Al}_{2} \mathrm{O}_{3}$, below a temperature of $0.6 T_{\mathrm{m}}$, the primary slip system $(0001)$ $\langle 1120\rangle$ has the lowest critical resolved shear stress and this system consists of a combination of only two slip planes and slip directions. However, five independent slips are required to produce homogeneous plastic deformation in polycrystalline solids. The operation of only two slips from the primary slip system accounts for the anisotropic deformation.

The tetragonal zirconia polycrystalline material used for this study is stabilized with $\mathrm{Y}_{2} \mathrm{O}_{3}$. It consists mainly of fine tetragonal grains and very small amounts of cubic grains. This accounts for the ductile behavior of the material. The material in the indentation is depressed into the substrate without macro-cracks at the corners of the indentation. However, the cracks which are parallel to the edge of indentation formed within the indented region (Fig. 6) are due to the tensile stresses developed when the material indented. These cracks become more pronounced as the load and surface roughness increases. Miyoshi and Buckley $[35,36]$ have also reported a brittle wear process controlled by crystallographic planes in singlecrystal $\mathrm{SiC}, \mathrm{MgO}$ and $\mathrm{Mn}-\mathrm{Zn}$ ferrite materials.

\subsection{Stress states under indentors}

A wide range of stress states exist under an indentor [37]. These include a nearly hydrostatic compression directly beneath a static indentor, particularly if it is spherical, to high tensile stresses in the indented surface, particularly behind a sliding sphere. The various phases found in the tested ceramic materials respond differently to imposed stresses. Some phases have a low cleavage strength and others have low shear strength. Furthermore, the thin second phases will probably not respond as would a large body of that phase because of triaxial stresses imposed by differences in properties from that of the major phase.

\subsection{The influence of traction stresses}

Generally, the type and extent of material damage in sliding was similar to that in the static indentation tests. All the aqueous liquid environments also produced an increase in the extent of failure in all the materials. For the two-phase materials, that wear by a fatigue mechanism, the initiation as well as propagation of fatigue fracture resulting in material loss were accelerated by the aqueous environment. The fatigue process is strongly influenced by the environment.

The coefficient of friction in the sliding tests is given in Table 4. It is seen that the aqueous solutions lower the friction in the first pass of sliding. This occurs whether the test is done immediately after wetting or after soaking for $12 \mathrm{~h}$. This would indicate that there is a "lubricating" effect by the liquid rather than a phase change to produce a low shear strength surface layer. This point is supported by the observation that the coefficient of friction rises to the dry value (approximately 0.6 ) after only five passes of sliding. These five passes cause surface damage and roughening, which reduces the effectiveness of lubricants somehow. However, an interesting 
question arises as to the mechanism by which aqueous environments increase the surface damage rate, and by extension the wear rate of the materials. Ordinarily, a lower coefficient of friction implies a lower shear stress on the sliding surface which should produce less fracture. Apparently, the lower shear stress is offset by some influence of the aqueous solutions on crack propagation, either in one pass of sliding or over several passes. This point requires more exploration.

\section{Conclusions}

The current wear models for ceramics, based on material hardness and fracture toughness, fail to correlate with experimental results largely because these models fail to account for the responses of non-homogeneous materials to the tensile component of stress that exists in the non-homogeneous stresses imposed by contact. The mechanisms of material removal during the wear of ceramic materials consist of a combination of many processes which are further controlled by the microstructure of the materials.

During indentation in the ceramic materials used for this work there was micro-damage which was unique to each material. The material removal processes correlate with the microdamage from static indentation, for all environments and surface preparation methods.

This study has shown that both microfracture and plastic deformation occurred within the indented region of hot-pressed $\mathrm{Si}_{3} \mathrm{~N}_{4}$ and both are controlled by the glassy grain boundary phase. Hot-pressed $\mathrm{SiC}$, alternatively, does not plastically deform in the indented region but instead shows extensive grain boundary failure which resulted in grain loosening and removal, in both the indentation and the sliding tests. $\mathrm{Al}_{2} \mathrm{O}_{3}$ showed plastic deformation by slip within the grains. $\mathrm{ZrO}_{2}$ showed a behavior that resembles that of metal especially at lower loads; but some cracks appeared which are parallel to the indentation edge within the indented region.

It is clear that sliding damage to brittle materials is not totally or adequately expressed by such properties as hardness or fracture toughness, taken separately or together. If progress is to be made therefore in formulating models for the wear of ceramic materials it must be done in terms of material microstructure such as grain size, grain strength, amount of grain boundary phase and its strength, and also in terms of applied conditions such as load, environment and surface roughness.

\section{References}

1 M. Asnani and F. L. Kuonen, SAE Paper 850358.

2 J. Miyauchi and Y. Kobayashi, SAE Paper 850313.

3 P. Walzer, H. Heinrich and M. Langer, SAE Paper 850567.

4 H. E. Helms and S. R. Thrasher, Engineering Applications of Ceramic Materials, American Society for Metals, Metals Park, OH, 1985, p. 25.

5 W. D. Carruthers and G. L. Boyd, Engineering Applications of Ceramic Materials, American Society for Metals, Metals Park, OH, 1985, p. 32. 
6 B. North, Mater. Soc., (Spring 1984) 257.

7 K. H. Jack, Met. Technol., (July 1982) 297.

8 E. D. Whitney, Powder Metall. Int., (April 1983) 201.

9 T. A. Libsch, P. C. Becker and S. K. Rhee, Wear, 111 (1986) 263.

10 N. Wallbridge, D. Dowson and E. W. Roberts, in K. C. Ludema (ed.), Proc. Int. Conf. on Wear of Materials, Reston, VA, April $11-14,1983$, American Society of Mechanical Engineers, New York, 1983, p. 202.

11 P. Sutor, Ceram. Eng. Sci. Proc., 5 (1984) 461.

12 D. C. Crammer, J. Mater. Sci., 20 (1985) $2029-2037$.

13 R. L. Agham and R. McPherson, J. Am. Ceram. Soc., 56 (1973) 46 - 47.

14 I. A. Cutter and R. McPherson, J. Am. Ceram. Soc., 56 (1973) 266 - 269.

15 T. F. Page, G. R. Sawyer, O. O. Adewoye and J. J. Wert, Proc. Br. Ceram. Soc., 26 (1978) 193 - 203.

16 Y. Enomoto and K. Yamanaka, in K. C. Ludema (ed.), Proc. Int. Conf. on Wear of Materials, Reston, VA, April 11-14, 1983, American Society of Mechanical Engineers, New York, 1983, p. 174.

17 B. Lawn and R. Wilshaw, J. Mater. Sci., 10 (1975) 1049.

18 T. Sugita and A. Hashikawa, Wear, $72(1981) 295-303$.

19 P. H. Mehortra, in K. C. Ludema (ed.), Proc. Int. Conf. on Wear of Materials, Reston, VA, April 11-14, 1983, American Society of Mechanical Engineers, New York, 1983, pp. $194-201$.

20 J. E. Hines, R. C. Bradt and J. V. Biggers, in K. C. Ludema, W. A. Glaeser and S. K. Rhee (eds.), Proc. Int. Conf. on Wear of Materials, Dearborn, MI, April 16 - 18, 1979, American Society of Mechanical Engineers, New York, 1979, pp. 540 - 550.

21 T. F. J. Quinn and W. O. Winer, Development of a theory of wear of ceramics, $Q$. Prog. Rep., Tribology Project, 1985, DOE-ECUT, p. 37.

22 T. E. Fischer and H. Tomizawa, in K. C. Ludema (ed.), Proc. Int. Conf. on Wear of Materials, Vancouver, April 14-18, 1985, American Society of Mechanical Engineers, New York, 1985, p. 22.

23 A. G. Evans, M. E. Gulden and M. Rosenblatt, Proc. R. Soc. London, Ser. A, 361 (1968) 343.

24 A. G. Evans and R. Wilshaw, J. Mater. Sci., 12 (1976) 97.

25 A. G. Evans and R. Wilshaw, Acta Metall., 24 (1976) 939.

26 M. V. Swaim, in R. C. Bradt (ed.), Fracture Mechanics of Ceramics, Vol. 3, 1978, p. 257.

27 M. A. Moore and F. S. King, Wear, 60 (1980) $123-140$.

28 A. G. Evans and D. B. Marshall, in D. A. Rigney (ed.), Fundamentals of Friction and Wear of Materials, American Society for Metals, Metals Park, OH, 1981, p. 439.

29 A. W. Ruff and S. M. Wiederhorn, in C. M. Preece (ed.), Treatise of Material Sci. and Tech., Vol. 16, Academic Press, New York, 1972, p. 69.

30 S. M. Wiederhorn and B. J. Hockey, J. Mater. Sci., 18 (1983) $766-780$.

31 J. L. Routbort and Hj. Matzke, J. Mater. Sci, 18 (1983) 1491 - 1496.

32 C. R. Dimond, J. N. Kirk and J. Briggs, in K. C. Ludema (ed.), Proc. Int. Conf. on Wear of Materials, Reston, VA, April $11-14,1983$, American Society of Mechanical Engineers, New York, 1983, p. 33.

33 Y. Tajima and W. D. Kingery, J. Mater, Sci., 17 (1982) $2289-2297$.

34 R. W. Armstrong and C. C. Wu, J. Am. Ceram. Soc., 61 (1978) 102.

$35 \mathrm{~K}$. Miyoshi and D. H. Buckley, in S. K. Rhee, A. W. Ruff and K. C. Ludema (eds.), Proc. Int. Conf. on Wear of Materials, San Francisco, CA, March $30-A$ pril 1, 1981, American Society of Mechanical Engineers, New York, 1981, pp. 501 - 509.

$36 \mathrm{~K}$. Miyoshi and D. H. Buckley, ASLE Trans., 28 (3) (1985) 296- 302.

37 D. Tabor, Indentation hardness and its measurement. In P. Blau and B. R. Lawn (eds.), ASTM Spec. Tech. Testing Publication 889, 1985, pp. 129 - 159. 